\title{
The Fifth Conference on Plasma Physics and Controlled Nuclear Fusion Research
}

The International Atomic Energy Agency (IAEA) will sponsor its Fifth Conference on Plasma Physics and Controlled Fusion Research at Tokyo, Japan, between 11 and 15 November 1974. The topics to be discussed will include the following:

(i) Experimental and theoretical investigations in plasma confinement systems

(ii) Plasma production, heating and stabilization

(iii) Plasma behaviour

(iv) Interaction of plasmas with radiation and particles

(v) Fusion reactor concepts

Selection of contributed papers will be made by the IAEA on the basis of summaries (1200 words) to be submitted by authors to their respective Government Atomic Energy Authorities. Summaries are due at the IAEA by 16 April 1974. 


\section{JOURNAL OF PLASMA PHYSICS}

\section{Volume 11 Part 1 February 1974}

\section{CONTENTS}

Effect of neutral gas friction and ion viscosity on the Rayleigh-Taylor instability of a stratified plasma in the presence of Hall currents

P. K. BHATIA

Extension of Dougherty's model Fokker-Planck equation for a plasma

R. J. PAPA

Attenuation of longitudinal electro-acoustic waves in a plasma

R. J. PAPA and P. LINDSTROM

Oblique and skew ionizing shock waves with non-unique structure

B. P. LEONARD

A note on the application of Whitham's method to nonlinear waves in dispersive media

K. B. DYSTH

Plasma losses through an adiabatic cusp

A. S. KAY E

Mass motion and heating in a magnetic neutral point system

P. J. BAUM and A. BRATENAHL

Decay instability of circularly polarized waves into circularly polarized and Langmuir waves in a magnetized plasma.

K. F, LEE

Absorption coefficients of a hydrogen plasma for laser radiation

J. R. STALLCOP

Experimental verification of the reciprocity theorem for antennas and electron plasma waves

Y. NAKAMURA and T. ITOH

Relaxation oscillations in weak turbulence. The case of nonlinear wave-particle interaction

C. MONTES

Transport properties of the three-dimensional guiding-centre plasma

G. VAHALA

REviEWS

Laser interaction and related phenomena, vol. 2, Edited by $H . J$,

Schwarz and H. Hora

Coronal expansion and solar wind, by A.J. Hundhausen

C. Cambridge University Press, 1974

CAMBRIDGE UNIVERSITY PRESS

BENTLEY HOUSE, 200 EUSTON ROAD, LONDON NW1 2DB

AMERICAN BRANCH: 32 EAST 57TH STREET, NEW YORK, N.Y. 10022

Annual subscription $£ 32.00$ net in U.K. (US $\$ 104.00$ in U.S.A. and Canada)

Printed in Great Britain at the University Printing House, Cambridge 